\title{
DISERTACIONES
}

Grupos minoritarios y estigmatizados: diversidad funcional, religiosa, étnica, afectivo-sexual o de identidad de

\section{RESISTENCIA Y DESIGUALDAD. CINE DOCUMENTAL ETNOGRÁFICO EN COLOMBIA}

Resistance and Inequality. Ethnographic Documentary Cinema in Colombia Resistência e desigualdade. Filme documentário etnográfico na Colômbia

Pablo Calvo de Castro, Universidad de Salamanca (España)

pablocalvo@usal.es

Recibido: 28 de septiembre de 2021

Aprobado: 29 de octubre de 2021

Fecha de prepublicación: 21 de enero de 2022

\section{RESUMEN}

El presente texto analiza la relación entre el mundo indígena, la cinematografía documental y el audiovisual como artefactos de representación en Colombia. Mediante una selección y revisión historiográfica de películas documentales que visibiliza títulos representativos de cada periodo, se analizó la intrincada relación entre la antropología visual, la identidad indígena y sus estrategias comunicativas, la evolución de los procesos de representación y la intensa vinculación de todos estos factores con el cine documental de corte etnográfico. Todo en un contexto histórico y social complejo, afectado por numerosos factores. Esta evolución contribuye a explicar las características actuales del cine documental de corte etnográfico en Colombia, conectado con el documental de autor en un momento en el que el discurso reflexivo se ha instalado en el formato documental. Hay que resaltar el papel que ha desempeñado el cine documental como formato por excelencia para la representación de las poblaciones indígenas. La evolución general de la cinematografía documental colombiana y latinoamericana, así como las transformaciones que han sufrido los enfoques teóricos en la antropología visual frente al objeto de estudio, han influido en la configuración de un tipo de cine que hoy enfrenta grandes retos en cuanto a las formas de representación.

Palabras clave: cine etnográfico; documental colombiano; representación indígena; autorrepresentación; correpresentación. 


\section{DISERTACIONES}

\section{ESTUDIOS}

Grupos minoritarios y estigmatizados: diversidad funcional, religiosa, étnica, afectivo-sexual o de identidad de género en la comunicación

ISSN: $1856-9536$

Doi: https://doi.org/10.12804/revistas.urosario.edu.co/disertaciones/a.11149

Volumen 15, Número 1 / Enero-junio 2022

Versión PDF para imprimir desde

http://revistas.urosario.edu.co/index.php/disertaciones

\section{ABSTRACT}

This article studies the relationship between the indigenous world and documentary filmmaking as well as the audiovisual industry as a representative medium in Colombia. By selecting and making an historiographical state of documentary films highlighting the type of representative titles prevalent in each period, we analyze the intricate relationship between visual anthropology and the indigenous identity, together with the strong association of these factors to ethnographic documentary films. All of these aspects being studied are parts of complex historical and social contexts affected by multiple factors. This evolution contributes to shaping the characteristics of contemporary ethnographic documentary filmmaking in Colombia, which remains associated with the authored documentary style at a time when the reflective speech documentary style has become immensely popular. The role played by documentary cinema as the primary medium of representing indigenous peoples is noteworthy. The overall evolution of Colombian and Latin American documentary filmmaking, coupled with shifts in the theoretical approaches in visual anthropology with regard to the subject being studied, has paved the way for a type of filmmaking that is now faced with significant challenges in terms of the forms of representation.

Keywords: Ethnographic filmmaking; colombian documentary; indigenous representation; self-representation; co-representation.

\section{RESUMO}

Este texto analisa a relação entre o mundo indígena e a cinematografia documental e audiovisual como artefatos de representação na Colômbia. Através de uma seleção e revisão historiográfica de filmes documentários que dão visibilidade aos títulos representativos de cada período, analisamos essa intrincada relação entre a antropologia visual, a identidade indígena e suas estratégias de comunicação, a evolução dos processos de representação e a intensa ligação de todos esses fatores com o cinema documentário. Tudo em um contexto histórico e social complexo, afetado por inúmeros fatores. Essa evolução contribui para explicar as características atuais do cinema documentário etnográfico na Colômbia, vinculadas ao documentário de autor em um momento em que o discurso reflexivo se instalou no formato documental. É necessário destacar o papel que o cinema documental tem desempenhado como formato por excelência de representação das populações indígenas. A evolução geral das cinematografias documentais colombianas e latino-americanas, bem como as transformações pelas quais passaram as abordagens teóricas da antropologia visual em relação ao objeto de estudo, influenciaram a configuração de um tipo de cinema que hoje enfrenta grandes desafios em termos de formas de representação.

Palavras-chave: cinema etnográfico; documentário colombiano; representação indígena; autorrepresentação; corepresentação. 


\section{DISERTACIONES}

ESTUDIOS

\section{Introducción}

Colombia cuenta con 87 poblaciones indígenas que atesoran una gran diversidad étnica en el contexto de América Latina. Además de los tres grupos de población afrocolombiana y el grupo Rrom o gitano, las identidades indígenas precolombinas surgidas del contacto con los inmigrantes hispanos componen un mapa multicultural que, desde comienzos del siglo xx ha mantenido una complicada relación con el cine y sus procesos de representación. Las constantes tensiones y la desigualdad estructural en los intercambios culturales heredados desde la época colonial no establecieron un escenario idóneo para estrechar lazos en favor del conocimiento mutuo. La llegada del conflicto a Colombia, que surge a partir de manifestaciones de extrema violencia en las zonas rurales en las décadas de los cuarenta y los cincuenta, también marcó a los colectivos indígenas, pues han visto afectados sus territorios y modos de vida. La presencia de grupos guerrilleros, paramilitares, narcotraficantes, bandas organizadas dedicadas a la minería ilegal, así como las incursiones del ejército, han marcado la historia reciente del campo colombiano. Esto desencadenó una reacción de resistencia en una colectividad fuertemente organizada ante las estructuras oficiales y foráneas en las zonas campesinas habitadas mayoritariamente por colectivos indígenas. El inequitativo reparto de tierras, el desplazamiento forzado, la violencia, las desapariciones y el asesinato, son solo algunas de las amenazas a las que se deben enfrentar pueblos cuya identidad cultural se ha visto afectada además por un proceso alienante de aculturación derivado de la homogeneización del discurso emanado desde los estamentos gubernamentales.

Desde las primeras propuestas de cine silente hasta los documentales de corte reflexivo y los procesos de autorrepresentación impulsados desde la academia con las propias comunidades, analizamos cómo la llegada de avances técnicos como la tecnología de vídeo y, sobre todo, los soportes digitales de registro, edición y distribución, ha supuesto un verdadero cambio de paradigma, consolidando una "estrategia de resistencia cultural" (Castells i Talens, 2003, p. 52) para muchas comunidades. Además, la influencia de la televisión como soporte de exhibición modificó, desde la década de los ochenta, la manera en que se configuran los discursos narrativos en el documental de corte etnográfico, desarrollando una curiosa convivencia de discursos que incluyen el registro de manifestaciones culturales y folclóricas, el conocimiento de culturas con escaso contacto con el modelo de desarrollo occidental y la denuncia de las injusticias sociales cometidas contra comunidades campesinas.

\section{Evolución del cine documental etnográfico en Colombia}

El cine documental en Colombia, como en la mayoría de los países del mundo, nace con el propio cine (Chaparro Valderrama, 2006) ya que el cinematógrafo se utiliza en un primer momento para documentar la realidad, tanto en escenas cotidianas como en celebraciones y ceremonias oficiales (Ramírez, 2015). Coincidiendo con el cambio de siglo, los enviados de la factoría Lumière ceden su lugar a los primeros productores cinematográficos en Colombia. Fueron los hermanos Di Doménico los que rodaron y exhibieron aquellos proto-documentales como El escudo de Antioquia, Retratos de los próceres y del presidente de la República e Hidroplanos, producidos alrededor de 1913. Otro italiano, Floro Manco, realizó De Barranquilla a Cartagena (1916) el primer largometraje, también documental, realizado y exhibido en el país (Nieto Ibáñez, 1997). 


\section{DISERTACIONES}

Llegaría después Manizales city de Félix Restrepo (1925), realizada durante la conmemoración de los 75 años de la ciudad. Al montaje original se le añadieron, unos meses después, imágenes de las ruinas tras el incendio que ese mismo año devastó la ciudad.

En este periodo, durante las décadas de los veinte y treinta, "aparecen las primeras imágenes fílmicas de indígenas colombianos; [...] mostrado ante todo como figura exótica y elemento del decorado" (Mateus Mora, 2012, p. 16), en la línea de esa primera antropología que contribuye en gran medida a la configuración de los relatos de poder que afianzan la postura neocolonial en décadas sucesivas. Los hermanos Gonzalo y Álvaro Acevedo Bernal, pioneros del cine colombiano, filmaron imágenes de indígenas en el Chocó en situación de contacto inicial (Díaz Cañadas, 2006), la Sierra Nevada de Santa Marta y la frontera con Perú. Estos primeros documentos visuales, al igual que ocurre con títulos como la brasileña Ao redor do Brasil: Aspectos do interior e das fronteiras brasileiras de Thomaz Reis (1932), son impulsados desde las cabeceras administrativas comandadas por militares en lugares remotos, y tienen como objetivo fundamental la puesta en valor de estos territorios mostrando sus recursos naturales y su exotismo tropical. Expedición al Caquetá de César Uribe Piedrahita (1930-1931) experimenta el mismo proceso, representando a los colectivos indígenas que documenta desde el punto de vista exótico. Este cortometraje de seis minutos de duración muestra a los miembros de la comunidad posando estáticos ante la cámara. El equipo de filmación no se interesa por la identidad cultural indígena, en tanto todavía no se observa un interés científico por estas formas de vida. Gonzalo y Álvaro Acevedo Bernal también dirigen en este periodo Colombia Victoriosa (1933), documentando y reconstruyendo parte de la guerra que enfrentó a Colombia y Perú entre 1932 y 1933 (Mora Forero \& Carrillo, 2003). Otra de sus aportaciones a este primer documental en Colombia es Olaya Herrera y Eduardo Santo, o de la cuna al sepulcro (1937) el primer largometraje de no ficción realizado en el país.

En las décadas de los cincuenta y los sesenta se produjeron con gran intensidad actividades evangelizadoras en las zonas remotas del país, proceso que no escapa a la mirada del cine etnográfico. El indígena es representado como "un ser bárbaro, sin cultura, que ha de ser salvado por el misionero portador de la verdad y la civilización" (Mateus Mora, 2012, p. 16). Prueba de ello es la película del padre claretiano Miguel Torres, Amanecer en la selva (1950), que solamente confirma esta fase en la que el cine etnográfico, como prueba visual del descubrimiento antropológico, se convierte en una herramienta al servicio de la proyección de la intensa actividad de cristianización misionera. La cinta está dividida en cinco secuencias que corresponden a cinco jornadas de trabajo de los misioneros. Aunque tiene un espíritu y una estética claramente documental en su vocación de acercarse a la realidad -observada en imágenes registradas de forma espontánea-, la mayoría de las acciones son preparadas previamente para ser representadas ante la cámara. Los miembros de la comunidad indígena se prestan a la representación por parte de los misioneros. Son mostrados como seres embrutecidos por la falta de desarrollo.

Durante la cuarta jornada se observa una sencilla trama sustentada en el conflicto generado en la convivencia entre los indígenas. El misionero, que además es el encargado de impartir justicia e inculcar los valores intrínsecos al desarrollo social y moral de la visión cristiana del mundo, aparece como salvador ante las actitudes delincuenciales y violentas.

En los primeros contactos se observa al hombre blanco vistiendo al indígena con ropas de colonos, que son entregadas como un regalo y un estímulo para favorecer los procesos de interacción. Dichos procesos derivan en la representación visual donde se produce una equiparación del indígena - cosificado-, con la fauna y la flora de esos lugares remotos del pacífico colombiano, en los que los misioneros llevan a cabo su trabajo. Los indígenas 


\section{DISERTACIONES}

posando vestidos, son prueba de la consecución de los objetivos de los misioneros en una cinta claramente diseñada para mostrarle al mundo la generosa labor de este equipo de religiosos. Logran que el indio abandone sus prácticas culturales y abrace el cristianismo, que también implica asumir la pertenencia al Estado colombiano, cuestión ajena para las culturas indígenas.

Se puede observar cómo la narración asume un punto de vista en el que el modelo de vida tradicional indígena genera un vacío existencial y social. Se muestra así un total desinterés por entender los constructos sociales y culturales que marcan la vida de esta población, de la que ni siquiera se indica su nombre. En esta falta de denominación se encarna la primera muestra de deslegitimación de la identidad indígena, y en los actos de alienación justificados por la salvación de las almas impías se manifiesta el gesto imperialista y colonial que contribuye a la configuración de una narrativa que va a influir en los procesos de representación de las comunidades en Colombia y en América Latina en general.

Ya en la década de los sesenta, el antropólogo Vidal Antonio Rozo dirigió Almas indígenas (1962) y El Valle de los Arhuacos (1964) (Bermúdez Rothe, 1995). Rozo analiza el tema indígena desde el impacto del progreso, todavía sin aplicar los cambios narrativos y formales que ya se muestran en estos momentos. Si bien en este caso se les otorga un mayor papel protagónico a los indígenas como cooperadores necesarios para el desenlace de la trama, "las autoridades espirituales y comunitarias de los indios son representadas con burla, sus símbolos y espacios sagrados son una vez más desvalorizados y despreciados" (Mateus Mora, 2012, p. 25). Ocurre de manera similar con Colombia, paraíso de América (1967) en la que Juan Ocampo viaja por el país rodando lugares y gentes, entre las que están distintas comunidades indígenas. Sin ser una película de corte etnográfico introduce el tema indígena desde un punto de vista folclórico, equiparando las poblaciones a paisajes o edificios.

Por otra parte, Gabriela Samper realiza una aproximación crítica a temas nacionales principalmente abordando las manifestaciones culturales colombianas amenazadas (Pizano, 2005). Algunos de los títulos más representativos son Festival folclórico de Fómeque (1964), El páramo de Cumanday (1965) - producida por la compañía petrolera Esso, en la que redefine el cine institucional, a la manera que lo hiciera Robert Flaherty en Louisiana Story (1948)-, Cuadrillas de San Martín (1968), Los santísimos hermanos (1969) y El hombre y la sal (1969).

Samper vivió durante algunos años en Estados Unidos y quizá sea esa la razón por la cual aporta en sus películas una visión diferente de la realidad social colombiana, con sus carencias, pero también con su potencial.

Además de ser una de las documentalistas más trascendentes de la historia de Colombia (Ruffinelli, 2016), fue una cineasta adelantada a su tiempo. Tanto desde el punto de vista social como desde una perspectiva puramente etnográfica, el cine de Samper puso las bases para la irrupción de los nuevos cines en el país.

De su filmografía, Los Santísimos Hermanos (1969) es la que tiene un enfoque etnográfico más incisivo (Torres San Martín, 2015). Aborda la situación de la secta mesiánica de Los Santísimos Hermanos, que "surge en el periodo de violencia extrema contra los campesinos en la región de Cundinamarca" (Calvo de Castro, 2017, p. 290). Junto a La orden de los Santísimos Hermanos de Enrique Pulecio (1977) es la única película documental sobre este grupo.

A nivel formal, aporta novedosas estrategias de documentación desde la investigación antropológica. Entiende la antropología visual como antropología de la comunicación visual donde se "problematiza la producción del film etnográfico como pregunta de investigación" (Ruby, 2007, p. 23). Establece un cambio de paradigma que influye en la postura del realizador frente a la realidad que documenta con colectivos y comunidades fuertemente organizadas a partir de la denominada Segunda Emergencia Indígena (Bengoa, 2000, 2009; Escárzaga, 2004). 


\section{DISERTACIONES}

La película, articulada en torno al discurso de uno de los representantes de la secta, comienza y acaba con la imagen de un texto escrito a mano en el que se postulan parte de los planteamientos que rigen este movimiento de rechazo a las instituciones establecidas y a la sociedad occidental. Tras los textos, Samper introduce el sonido directo para capturar el discurso - que en ningún momento aparece en imagen-. Esta transita de manera independiente como alocución referencial complementaria a la narración mezclando imágenes cinematográficas con otras fotográficas que se circunscriben, en la mayoría de los casos, a fragmentos de cuerpos y detalles de actividades. Este estilo de registro puede responder a una coherencia formal con respecto al contenido filmado, ya que los miembros de Los Santísimos Hermanos muestran y utilizan solo el lado izquierdo de su cuerpo. Por este motivo deben ayudarse entre dos personas para realizar acciones donde es necesario utilizar las dos manos, generando así un curioso ritual en el que trabajan dos manos izquierdas para muchas tareas cotidianas.

La premisa para Samper era clara, lograr una relación de confianza con las personas filmadas. Eso solo era posible a partir de la convivencia durante largos periodos de tiempo en las comunidades. Gabriela Samper acompañada de Rebeca Puche, estudiante de psicología, y Hernando Sabogal, estudiante de antropología, se embarcaron en un rodaje de seis meses con una cámara de $16 \mathrm{~mm}$ en blanco y negro (Ruffinelli, 2012). Realizada con medios precarios, produjo una fotografía incompleta y en algunos casos insegura. Se puede hablar de una fotografía incompleta en tanto la cinta adolece de variedad en el encuadre, predominando el primer plano y el plano detalle. La cámara busca los rostros de las personas, los detalles de su cuerpo y de los sacos que tapan el lado derecho del mismo. Insegura, produce imágenes inestables fruto de la inexperiencia de su director de fotografía, un estudiante de antropología. Pero esta falta de variedad en el encuadre se compensa con un montaje que aporta un gran ritmo narrativo y establece un paralelismo entre la imagen y la banda sonora en el que, como ocurre en Hermógenes Cayo (Imaginero) - película argentina de Jorge Prelorán (1969) - , se marca un nivel de referencialidad independiente y complementario que impulsa la renovación del documental etnográfico en la década de los sesenta. A partir del respeto y la comunicación pausada con las comunidades documentadas se introduce una pauta en la que el realizador-antropólogo logra captar documentos singulares influyendo en películas posteriores como Chircales (1972) o Nuestra voz de tierra. Memoria y futuro (1976-1981) de Marta Rodríguez y Jorge Silva.

Tras sufrir la represión del régimen de Pastrana, que la torturó y encarceló acusada de pertenecer a la guerrilla del Ejército de Liberación Nacional colombiano a comienzos de los setenta, se truncó su vida y la carrera cinematográfica de una mujer diferente, cuya obra supuso una gran contribución al aumento de la presencia femenina en la esfera intelectual y cinematográfica colombiana.

Es durante la década de los setenta cuando el cineasta con vocación etnográfica también se ve influido por las nuevas teorías que nutren disciplinas como la sociología, la economía política de orientación marxista, la ecología crítica o el feminismo. Estos movimientos apoyan la consolidación del Nuevo Cine Latinoamericano (León Frías, 2013; Elena \& Mestman, 2003), primer punto de inflexión en la historia del cine documental en la región (Calvo de Castro, 2019).

En ese momento, corrientes de cambio social que se producen a nivel general en América Latina como las disidencias políticas de las décadas de los cincuenta, sesenta y setenta, las migraciones del campo a la ciudad de grandes grupos de población o del desarrollo del sindicalismo campesino y minero, contribuyeron a cambiar el eje de autoridad de la mirada. 


\section{DISERTACIONES}

En el contexto colombiano confluyen distintas corrientes que apoyan este cambio de paradigma, también en el documental etnográfico. La renovación introducida en el ámbito mundial por la Nouvelle Vague francesa y el Nuevo Cine Latinoamericano, muy marcado a su vez por el neorrealismo italiano, son las principales. En un contexto en el que los cineastas sienten la necesidad del cambio frente a las temáticas, la estética y los argumentarios imperantes durante e inmediatamente después de la Segunda Guerra Mundial, el documental colombiano experimenta una fuerte polarización que, como indica Juan Guillermo Ramírez (2015) asume tres caminos claramente diferenciados: el poético, el político y el etnográfico. En la década de los setenta aparece, por una parte, una corriente de documental político bajo el influjo de los grupos argentinos Cine de la Base y Cine Liberación, y por la facción más militante del documental cubano producido por el IcAlc. Cineastas como Juan José Vejarano, Norman Smith, Hernando González, Diego León Giraldo o Carlos Álvarez son algunos de los que asumieron esta corriente. Por otro lado, aparece el documental poético, que incorpora la retórica en la narrativa y trata de mostrar los resultados de la investigación previa a la película a través de mecanismos discursivos que denotan cierta inquietud estética en la configuración de la obra. Chircales (1966-1971) de Marta Rodríguez y Jorge Silva es un caso representativo de los distintos caminos que va asumiendo el cine documental en este periodo. Lo hace a través de una mirada etnográfica, pero también política y poética con un gran valor como herramienta de investigación social con intención estética (Ramírez, 2015). Este proceso vuelve a aparecer en Planas, testimonio de un etnocidio (1971), también de Marta Rodríguez y Jorge Silva. Con una factura mucho más urgente, se observa cómo introduce el factor social denunciando la vulneración de derechos de las comunidades indígenas, otorgando la enunciación del discurso a los miembros de la comunidad. Este documental influye en películas como El pecado de ser indio de Jesús Mesa García (1975), Nuxka de Manuel Franco (1974), Wana Tummat, Madre tierra de Roberto Triana (1975) o El indio sinuano de Carlos Sánchez (1976). Se identifica también Actividad del grupo indígena en Colombia de Jairo Pinilla (1976), un retrato sobre la comunidad emberá que huye del exotismo, un rasgo que regresa a la realidad cinematográfica de Colombia de la mano de Amazonas para dos aventureros de Ernst Hofbauer (1974) o Amazonas: infierno y paraíso de Rómulo Delgado (1980) y que parecía ya superado en el documental etnográfico de este periodo.

En todo caso, la corriente de cine político discurre por un itinerario con identidad propia -derivado de lo limitado de las temáticas, así como de su fin último desde su gestación: la movilización política- aunque las temáticas indígenas incorporen el enfoque social en sus discursos, influencia clara de esta corriente. Por su lado, el documental poético va a confluir con otros modelos, entre ellos el etnográfico, en una práctica común cuando se analiza cualquier tipo de corriente documental, la hibridación y adaptación constante de los discursos como fórmula narrativa producto de la inquietud de cada realizador.

En este punto se inicia la producción de un verdadero documental etnográfico colombiano en tanto se observa la inclusión sistemática de una fuerte carga de denuncia social en los discursos narrativos. Este es el verdadero factor diferencial respecto a otras modalidades de representación en el documental y los periodos anteriores ya analizados.

El enfoque antropológico que introducen primero cineastas como Gabriela Samper se ve apoyado por dos cambios importantes en el contexto político-social y cultural. El primero se produce en 1971 con la creación del Consejo Regional Indígena del Cauca (CRIC) con el que trabajarán intensamente Marta Rodríguez y Jorge Silva, además de realizadores como Jesús Bosque. El segundo factor, de orden cultural, tiene que ver con el posicionamiento que asume la antropología como ciencia en este momento de cuestionamiento global que se vive tras la Segunda Guerra Mundial. 


\section{DISERTACIONES}

Todos estos aspectos estimulan el cambio de papel del cineasta respecto a la realidad observada, también en lo relativo al documental de corte etnográfico. Se produce un "redescubrimiento del indígena, [...] que pasa a ser un sujeto social y político que se enfrenta a la violencia terrateniente y oficial, y lucha por sus derechos" (Mateus Mora, 2012, p. 16). Ese replanteamiento desliga la antropología de los roles de superioridad por parte del investigador ante culturas consideradas primitivas, para asumir el método científico desde un plano de respeto adscrito a los lineamientos de autores como Levi-Strauss (2005, p. 102), quien afirma que "la humanidad no evoluciona en un sentido único" y, por tanto, debe ser analizada tomando en cuenta la multiculturalidad y la multiplicidad de discursos.

Un ejemplo significativo de esta corriente es Nuestra voz de tierra. Memoria y futuro de Marta Rodríguez y Jorge Silva (1976-1981). Si bien Marta Rodríguez ha transitado por la senda de lo social a lo largo de su extensa carrera como documentalista en Colombia, la mirada a los colectivos indígenas y campesinos siempre ha ocupado un lugar predilecto en su cinematografía. En ese sentido, aunque Chircales (1972) es el título que más ha impactado a nivel social dentro de la cinematografía documental colombiana, Nuestra voz de tierra. Memoria y futuro (19761981) es una cinta que merece una observación especial en el presente texto por todas sus aportaciones tanto en el plano cinematográfico como etnográfico. Protagonizada por miembros de la comunidad indígena coconuco, desde un punto de vista implicado y militante con la causa indígena, la película narra la lucha de esta comunidad por defender su territorio ante la invasión de la población colona campesina -no indígena- y los grandes terratenientes que han acaparado considerables extensiones del país desde su posición de privilegio en la oligarquía tradicional. El inequitativo reparto de tierras es uno de los principales problemas de convivencia entre población colona e indígena en América Latina, y en el contexto colombiano contemporáneo es uno de los factores que ha contribuido a generar y perpetuar el conflicto armado desde mediados del siglo pasado hasta la actualidad.

Rodríguez y Silva convierten los testimonios derivados de las entrevistas en el hilo conductor de la historia narrada en el documental. Mediante la incorporación de la primera persona del singular en la voz en off ceden el protagonismo de la enunciación a los propios indígenas. En este sentido, se observa una postura militante por parte de los cineastas que trata de compensar la invisibilización a la que son sometidas las comunidades indígenas por parte de la mayoría criolla. Mediante un montaje en paralelo, se refuerza la carga simbólica que tienen las imágenes del conquistador español frente a las de los campesinos indígenas. Se ubica así la fuente del conflicto en las raíces colonizadoras más ancestrales (Gómez Moreno, 2017) que han mantenido prácticas muy similares con distintos actores y las mismas víctimas a lo largo de la historia. Cabe recordar que Marta Rodríguez ha sido muy activa en el trabajo con las comunidades indígenas en Colombia, especialmente con el cRIc, quizá el organismo más dinámico en la defensa de los derechos y la identidad cultural indígena en el país, con el que ha producido títulos como Planas, testimonio de un etnocidio (1971), La voz de los sobrevivientes (1980), y las más recientes, Testigos de un etnocidio: memorias de resistencia (2011) y La sinfónica de los Andes (2018).

Estas representaciones, siempre dentro de procesos de construcción del relato que cuentan con la colaboración de la comunidad, tienen la función de servir como documento de preservación de identidades indígenas en riesgo de desaparición, pero también de denuncia de vulneraciones de derechos reconocidos constitucionalmente en el país.

Volviendo a Nuestra voz de tierra. Memoria y futuro (1976-1981), lo comentado anteriormente se observa a través de construcciones narrativas que generan una constante hibridación con la ficción a partir del simbolismo audiovisual, las representaciones de los hechos históricos utilizando intérpretes de la propia comunidad también 


\section{DISERTACIONES}

en el papel de los conquistadores o la carga emocional de la banda sonora. Un claro ejemplo de la combinación de estos elementos se identifica cuando Rodríguez y Silva incluyen imágenes de animales degollados cuya carne está secándose en la vivienda para su conservación, compaginados con la narración en off y la representación del terrateniente a través de un indígena caracterizado.

La película evoluciona hasta un estilo cinematográfico más directo que aúna la mencionada carga simbólica con la documentación de las acciones políticas de resistencia del cRIc como organización indígena y campesina frente a los terratenientes y la administración. Recuerda a algunos fragmentos de La batalla de Chile de Patricio Guzmán (1973), en ese estilo urgente practicado en el acompañamiento de las acciones de resistencia. Por otra parte, se conecta a la perfección con el ya comentado uso de la representación simbólica en las referencias a la identidad cultural y al pasado colonial, mediante un estilo poético que emana sobre todo de la identificación de la figura del diablo en la cosmogonía indígena y la colectividad campesina en su relación con el terrateniente y, en menor medida, el invasor extranjero como responsable del expolio de minerales en territorios indígenas.

Por último, este nivel múltiple de reflexión incorpora denuncias concretas sobre hechos que trascienden a la cuestión indígena, pero que afectan directamente a los colectivos como la vulneración de derechos ciudadanos, la usurpación de votos, el acoso por parte de los militares o el asesinato de líderes sociales.

Todos estos factores configuran una narración que persigue la generación de memoria a través de la recuperación histórica de los hechos desde un posicionamiento crítico.

Con la normalización del uso de la tecnología de vídeo como soporte de registro en la década de los ochenta se produjo la consolidación y primera gran expansión del género documental en la cinematografía colombiana. En paralelo, los distintos canales de televisión nacionales y regionales - sobre todo desde la televisión públicapermiten el desarrollo de contenidos en formato de serie documental que introduce también la representación etnográfica. Nos detenemos en este punto en dos series documentales: Yuruparí de Gloria Triana (1983-1986) emitida en RTVc y Rostros y rastros (1988-2000) emitida en Telepacífico, ambos canales de televisión pública.

En lo relativo a Yuruparí (1983-1986), analizamos dos capítulos de la serie, Cuadrillas de San Martín de Gloria Triana y Jorge Ruiz Ardila (1983) y Por los caminos reales del Corpus Christi de Ofelia Ramírez y Joaquín Villegas (1985), ambos con una serie de particularidades que encarnan las características de este tipo de documentales.

Cuadrillas de San Martín (1983) rememora hechos de la conquista a través de las cuadrillas, una festividad ecuestre de origen español que se celebra cada 11 de noviembre en el municipio de San Martín -departamento del Meta- desde 1735. Conectada a la fuerte identidad ganadera de la población de la región, la celebración rememora actos de origen colonial a los que se le suman las influencias indígenas y afrodescendientes.

Por los caminos reales del Corpus Christi (1985) reivindica, mediante cuatro secuencias claramente diferenciadas, la tradición de la población criolla colombiana heredera de aquellos primeros exploradores españoles. El concepto de los caminos reales, que comunican zonas remotas de Colombia a través de trazados de la época colonial, se utiliza como hilo narrativo. Hay que recordar que Colombia es atravesada de norte a sur por la Cordillera de los Andes y, si bien tiene extensas zonas de selva, llanos y sabana, las mayores concentraciones de población se producen en áreas montañosas con una orografía escarpada que dificulta la comunicación vial. Ofelia Ramírez y Joaquín Villegas recuperan los vestigios grabados en la piedra de estas poblaciones de la etnia panche que habitaron la cuenca del río Magdalena, pero que ya sufrieron un proceso de aculturación con el que desaparecieron como pueblo. Fueron las primeras poblaciones indígenas con las que se encontraron los conquistadores españoles tras cruzar la 


\section{DISERTACIONES}

cordillera en la exploración del reino de Nueva Granada. Se observa claramente la postura de observador foráneo que contribuye a configurar un relato ajeno al sujeto representado, sobre todo cuando la voz en off manifiesta que los indígenas panches finalmente sucumbieron a la opresión y a la pobreza, y luego de la llegada de los españoles colonos fueron agrupados en pueblos para ser evangelizados.

Tras la introducción, la cámara se fija en las manifestaciones folclóricas campesinas en torno a las celebraciones religiosas propias de la cultura campesina heredada de las haciendas coloniales, influidas por los ritmos andinos con los que entraron en contacto los españoles.

El objetivo fundamental de esta cinta, además del loable esfuerzo por plasmar evidencias audiovisuales de manifestaciones culturales de las áreas rurales, está en mostrarle al espectador colombiano -mayoritariamente urbano y desconectado de la realidad multicultural de un país tan diverso como Colombia- expresiones folclóricas que, si bien nada tienen que ver con el mundo indígena, forman parte de la identidad cultural del país. Es una visión que se asemeja a la del turista urbano que quiere conocer más del folclore de su país.

Gloria Triana, ideóloga y directora de la serie, desarrolla un tipo de producción documental que preserva prácticas culturales en riesgo de desaparición, en numerosas ocasiones, mediante su representación folclórica. Si bien se identifican falencias en lo relativo al papel del sujeto representado en el contexto de la evolución del tratamiento de la representación indígena, sirven como complemento en un espacio multicultural que se vio afectado también por la conquista española y las prácticas culturales que surgen de su influencia en distintos territorios en las relaciones establecidas entre comunidades nativas, afrodescendientes y criollas.

Durante este periodo, el panorama del documental de corte etnográfico se complementa con producciones documentales desarrolladas como obras cinematográficas que van a incorporar el vídeo como soporte de registro.

Este soporte, utilizado desde el punto de vista de la antropología visual, abre la vía para la autorrepresentación a partir de la capacitación de las poblaciones en proceso de lucha por la preservación de su identidad frente a los procesos de aculturación a los que se ven sometidos.

Los procesos de autorrepresentación indígena en América Latina hunden sus raíces en la escuela boliviana encabezada primero por Jorge Ruíz, y luego por Jorge Sanjinés y sus trabajos con comunidades indígenas quechua y aimara. Sanjinés pone en práctica fórmulas narrativas que establecen un diálogo entre los constructos sociales occidentales y los propiamente indígenas, permitiendo el uso del cine como soporte de registro y representación de los imaginarios indígenas. En la práctica, quizá la mayor muestra de este proceso se aprecia en el desarrollo de técnicas como el plano secuencia integral identificado en La nación clandestina (1989) (Flores, 2013) y sistematizado en las reflexiones teóricas sobre este fenómeno en ensayos como Teoría y práctica de un cine junto al pueblo (1979). Mediante el vídeo, el cineasta, sujeto activo del proceso de representación, puede pasar a un segundo plano a través de la capacitación de colectivos para el uso de la cámara en la generación de la propia imagen. Uno de los mayores exponentes de este fenómeno es, desde Brasil, Vicent Carelli. En su proyecto Vídeo nas aldeias ha producido más de 70 títulos que manejan distintos niveles de representación con comunidades de la Amazonía brasileña. La capacitación en el uso de herramientas audiovisuales permite a las comunidades indígenas preservar sus derechos, su cultura y su identidad (Gallois \& Carelli, 1992), cuestión que se refleja en la película brasilera A arca dos Zo'é de Vincent Carelli y Dominique Gallois (1993). En Colombia, iniciativas como la mencionada van a derivar, gracias a estructuras como el cRIc, en propuestas de autorrepresentación en las que no son los propios indígenas los generadores del discurso narrativo dentro del documental, sino que manejan la representación a 


\section{DISERTACIONES}

partir de observadores foráneos previamente admitidos en la comunidad para ese fin. Estas películas superan la barrera cultural para integrar su discurso en contextos diferentes al propiamente indígena de acuerdo con niveles de representación que incluyen la preservación de la identidad cultural y la denuncia de las injusticias cometidas contra las propias comunidades.

Si bien en el periodo anterior hemos analizado cómo la llegada del vídeo estimula la producción de series documentales para televisión que incluyen el enfoque etnográfico, abordamos a continuación el caso de Jesús Bosque. Este realizador español se integra durante la década de los noventa en la estructura del cRIc, con el que produce cuatro documentales: Caloto, un año después (1991), Küc' ' Wala, El Baile de los Negritos (1992), Nuestra lengua es importante (1993) y Na'wëthaw Püt, Así nos organizamos (1995).

El CRIC es una estructura fuertemente organizada de resistencia indígena frente a las políticas de la administración colombiana. Agrupa 16 poblaciones indígenas diferentes y en los últimos treinta años, como apunta Hernández Delgado (2006, p. 179) se ha "comprometido con unas propuestas y acciones no violentas en torno a la recuperación, el fortalecimiento y la protección de sus culturas, su ejercicio de autonomía, y el desarrollo de un proyecto político" frente al desigual e injusto reparto de tierras en sus territorios ancestrales a través de un sistema agropecuario propio de la colonia.

Aunque estos filmes documentales no introducen novedades en lo formal más allá de la utilización de cámaras de vídeo Betacam, que otorgan un registro de la realidad más flexible y cómodo para el cineasta, cabe señalar cómo este proceso de representación es "un caso paradigmático de procesos colaborativos entre el realizador-antropólogo y las comunidades para generar contenidos audiovisuales [...] que contribuyen a la preservación de la identidad cultural" (Calvo de Castro, 2021, p. 177), además de cuestionar la presencia del observador externo en los procesos de autorrepresentación que permean los procesos de representación indígena (Barranquero \& González Tanco, 2018), partiendo de la base de que, como apunta Marta Rodríguez (2013, p. 72) "en las culturas indígenas [del] Cauca se habla de un Yo colectivo", lo que hace más significativas, si cabe, las películas de Bosque.

Con el cambio de siglo se produce también un relevo generacional en el cine documental colombiano. Aparecen ahora un conjunto de realizadores influidos por los constantes replanteamientos que hace el cine documental a nivel general, pero también por los cambios que está sufriendo la sociedad colombiana. El cine documental más urbano se aleja de la visión antropológica indígena para observar, con una mirada etnográfica, los problemas urbanos del país mediante "textos audiovisuales en los que formas tradicionales de la estética documental como la cámara participante y la entrevista se mezclan con el vídeo clip o la dramatización” (Ramírez, 2015, p. 32). La influencia de Víctor Gaviria en esta nueva generación de cineastas es clara en títulos como Zona 2 мl-17 (2002) de Wilmar Quintero, Nelson Restrepo y Hélmer Atehortúa, El reino encantado (2002) de Óscar Molina, y, sobre todo, Colombia con sentido (2000), ¡Danza, Colombia! (2009) y Beatriz González ¿Por qué llora si ya reí? (2011) de Diego García Moreno, fundamentales para entender la diversidad que caracteriza el cine documental en Colombia en el siglo xxı. En el contexto de los medios digitales y de la expansión de las tecnologías de la información y la comunicación, "lo local se revaloriza, así como los movimientos culturales étnicos, raciales, regionales, de género, que reclaman el derecho a su propia memoria y a la construcción de sus propias imágenes" (Ramírez, 2015, p. 34).

La televisión, como medio masivo de difusión, convive con diversas plataformas digitales como YouTube, o en un contexto más regional, Retina Latina. En todas ellas el documental ha encontrado un nicho de exhibición que canaliza el trabajo desarrollado desde agrupaciones comunitarias, grupos de investigación en universidades 


\section{DISERTACIONES}

y diversos colectivos. Pero no solo el volcado de resultados desde la academia o el activismo social copan las inquietudes de los realizadores. La necesidad de visibilidad en un ecosistema de difusión saturado y la facilidad de acceso a los medios de producción digitales son dos de los factores que han hecho irrumpir con fuerza el factor estético para completar esta tríada que, de alguna manera, matiza la realidad de la creación documental en Colombia en el siglo xxı.

En la actualidad, Marta Rodríguez subraya las reflexiones de Juan Guillermo Ramírez (2015, p. 35) que indica que la televisión, como soporte de difusión del documental, introduce "un alto grado de información/espectáculo" que intoxica, de alguna manera, las propuestas documentales que tratan de referenciar los derechos de las comunidades indígenas. En concreto, esto ocurre con la representación manida y estereotipada que hace de las personas que pertenecen a comunidades indígenas la novela Diomedes, el Cacique de La Junta (2015) dirigida por Herney Luna y María Cecilia Vázquez, emitida por el canal RcN Televisión. En esta producción se muestra al indígena como un ser perverso que trata de engañar al criollo, tiene todos los vicios y asume el papel de villano desde su posición de subdesarrollo. Si bien hay que relativizar dicha representación por producirse en un formato, el de la telenovela, con una serie de roles y arquetipos que el espectador decodifica sin dificultad, también es cierto que en un periodo en el que son necesarios los esfuerzos por canalizar un mensaje constructivo sobre la representación de las comunidades indígenas, este tipo de producciones hacen suponer un retroceso, en tanto tienen un impacto en términos de audiencia muy superior al que logran las producciones documentales cinematográficas. Frente a este tipo de representaciones, los documentalistas reivindican miradas como la de Testigos de un etnocidio: memorias de resistencia de Marta Rodríguez (2009), la cual "busca articular la memoria colectiva con la memoria autobiográfica, como queriendo resaltar que la subjetividad se constituye en procesos sociales" (Mateus Mora, 2012, p. 18).

Desde la relación de las comunidades con la antropología visual en la actualidad, los siguientes títulos son representativos de los procesos de reflexión de las comunidades en torno a su representación en convivencia con modelos culturales que manan desde las propuestas gubernamentales. Nabusímake: memorias de una independencia del Colectivo de Comunicaciones Zhigoneshi (2011), es un caso de autorrepresentación que supera el impacto en el contexto exclusivamente indígena y articula el mensaje a través de modelos narrativos más globales. Sey Arimaku o la otra oscuridad de Pablo Mora Calderón (2012) sistematiza el proceso de representación por medio de la academia, la militancia y la preservación de la identidad cultural.

Con un fuerte componente de investigación, pues es resultado de un proyecto académico, Gustavo de la Hoz dirige El origen del pueblo Tikuna (2009). Se introduce una revisión de la evolución histórica del pueblo tikuna desde el punto de vista indígena. Mediante el registro documental de la transmisión oral se muestran las cuestiones definitorias de esta comunidad como sus creencias, valores, la labor del médico tradicional, los juegos, los rituales de cortejo, la pesca, la caza o los retos para conseguir una esposa. En esta parte, el director introduce una intensa carga simbólica plasmando en el formato cinematográfico la representación de los sueños, las leyendas y las tradiciones tikuna. Mediante animaciones y representaciones ficcionales, narrada casi en su totalidad en lengua indígena, $E l$ origen del pueblo Tikuna (2009) reivindica una visión histórica desde la propia comunidad en un acto de autorrepresentación que implica también la visión histórica de la relación ancestral con el otro que, en este caso, emana de la llegada de los españoles, quienes otorgaron la denominación tikuna a esta comunidad. En cuanto al uso de la representación simbólica, la película está en la línea títulos como Kata Ou-Outa (Vivir-Morir) de Patricia Ortega (2007), Shawantama'ana (Lugar de espera) de Yanilú Ojeda (2012) y Wachikua (Nuestra historia) de Aranaga Epieyu 


\section{DISERTACIONES}

(2014). Aunque son producidas en Venezuela, suponen un ejemplo perfecto de la representación de la sociedad wayuu, cuyo territorio ancestral está compartido entre Colombia y Venezuela. Aunque los dos primeros títulos son producidos por realizadoras que habitan en Maracaibo y están especialmente sensibilizadas con la realidad de la población wayuu, Aranaga Epieyu desarrolla un discurso de preservación de la identidad cultural desde la pertenencia a la comunidad wayuu, a la que regresa tras recibir su formación universitaria en comunicación audiovisual.

Alejandro Naranjo dirige La selva inflada (2015), una mirada íntima hacia la juventud indígena del área de Mitú. La de los protagonistas es una generación que ha accedido a la educación secundaria y vive totalmente aculturada por la sociedad de consumo, la religión y el ejército. Naranjo plantea cómo ante el trauma de la transición cultural y la falta de alternativas de estos chicos, la salida es el suicidio. Este problema ha trascendido con cifras preocupantes en sociedades que hasta la fecha habían cubierto las necesidades emocionales y sociales de sus individuos. No obstante, la transición hacia un modelo de convivencia normalizado desde el estándar occidental tiene una serie de consecuencias en el modo de vida tradicional. La película plantea cómo la destrucción del modelo de familia indígena y la desconexión de los individuos de su grupo social cuando acuden a estudiar a los centros urbanos, afecta negativamente a la salud psicosocial de los adolescentes y jóvenes. Del mismo modo, la necesidad de bienes de consumo y la imposibilidad de encontrar dinero para su adquisición provoca altas tasas de frustración, lo que lleva a muchos indígenas al consumo de sustancias estupefacientes introduciendo prácticas ajenas a su cultura.

La historia surge de una noticia publicada en el diario colombiano El Tiempo, que en el 2009 hacía eco de la delicada situación de muchas comunidades indígenas y la tendencia de muchos de sus miembros al suicidio. Esta información se conectaba con un informe de Unicef del 2012 en el que se alertaba sobre esta preocupante tendencia de jóvenes indígenas de distintos lugares del mundo. Es curioso observar que en ningún momento se indica la comunidad concreta a la que pertenecen los protagonistas. Pero no es este un ejemplo de observación del objeto de estudio silente, sino más bien, una orientación del punto de vista hacia una problemática sectorizada que no aborda una comunidad concreta para ser estudiada, representada o autorrepresentada, sino que afecta a las poblaciones indígenas de manera transversal. El hecho de que no se mencione el grupo étnico concreto define una singularidad cultural - sea cual sea- en conflicto frente al modelo occidental al que se exponen chicos y chicas de distintas comunidades indígenas cuando acuden al núcleo de población más grande a cursar la educación secundaria.

En primera persona y mediante un texto en pantalla, uno de los protagonistas de la película introduce un discurso final que abre espacios para la reflexión en el espectador. Transcribimos a continuación el texto completo:

Ya señalé antes que soy indígena. Debo agregar ahora que todos los indígenas del Vaupés tenemos riquezas espirituales y grandes carencias materiales. Mi pueblo necesita profesionales que lo saquen adelante y yo quiero ser uno de ellos. Pero para lograrlo debo empezar a estudiar en una universidad del interior del país, dentro de dos años y eso cuesta mucho dinero. Los derechos académicos, el arriendo, el transporte, la alimentación, las fotocopias... he visto parientes fracasar en el intento. Si todo sigue subiendo como hasta ahora, en mi familia no se podrá ahorrar para el pago de mis estudios universitarios. Si no logro ir a estudiar tendré que buscar un pequeño trabajo en Mitú o regresar a mi comunidad y no podré ayudarla como espero. Si eso no sucede pronto en este incierto panorama, seguramente seré tentado por la guerrilla, los paramilitares, la policía o el ejército para que ingrese a sus filas. O quizás algún narcotraficante me proponga opciones de vida en donde la inflación no tenga importancia. (Alejandro Naranjo, La selva inflada, 2015) 


\section{DISERTACIONES}

ESTUDIOS

Esta película es un ejemplo de cómo el documental de autor introduce una mirada alejada del enfoque etnográfico a una problemática social que afecta a numerosas comunidades indígenas, en constante conflicto cultural con la población colona y, sobre todo, con los modelos occidentales de desarrollo. En todo caso, el discurso de Alejandro Naranjo aporta un estímulo para la reflexión acerca de la multiculturalidad de la sociedad colombiana y un ejemplo de cómo las fricciones que genera la imposición de un modelo unitario en los contextos indígenas causan estragos en comunidades que se ven desbordadas para gestionar problemas que no son suyos. En este sentido, la inteligente estrategia de Naranjo permite al espectador establecer un contexto de empatía con la realidad indígena sin que haya que hacer una demostración evidente de identidad cultural en el discurso narrativo.

\section{Conclusiones}

Tras esta revisión de la evolución del cine documental de corte etnográfico en Colombia y algunos de sus títulos más representativos, en la actualidad encontramos un contexto de producción que ha tomado nota de las aportaciones y las reflexiones de décadas pasadas sobre la manera de abordar el objeto de estudio, el papel de autory los distintos niveles de representación discursiva que maneja el cine documental en la actualidad.

La relación de las comunidades indígenas con el cine documental etnográfico, una vez superado el rol de objeto de estudio silente introducido por la vocación científica de la antropología visual hasta mediados del siglo pasado, ha establecido un contexto ideal para la preservación de la identidad cultural y de la reivindicación de derechos. Por un lado, las comunidades indígenas llevan a cabo un proceso de apropiación de las herramientas para contar su historia mediante el cine documental. La generación de narrativas propias se ha perfeccionado y enriquecido mediante la incorporación de los realizadores a escuelas de cine y facultades de comunicación, para luego retornar a sus comunidades y construir y preservar imaginarios socioculturales que hasta ahora solo eran transmitidos de forma oral. Por otro lado, dentro de sociedades campesinas fuertemente organizadas, las producciones de cine documental en colaboración con miradas foráneas militantes con la causa indígena han visibilizado las demandas de colectivos que son silenciados en el discurso oficial colombiano. La difusión de sus mensajes por televisión en formato documental tanto a nivel nacional como internacional ha sido complementada en los últimos años por plataformas en Internet que permiten el acceso inmediato y gratuito de contenidos documentales que articulan el posicionamiento de las comunidades.

A esto se le suma la mirada del autor, que se conecta con la esencia del documental, pero también con la evolución general de este formato, que introduce un discurso con mayor carga reflexiva y elaboraciones narrativas más complejas que integran la fuerte carga simbólica de los imaginarios indígenas en un contexto de preservación cultural.

En Colombia, toda esta tendencia se ve matizada por la evolución del cine documental a nivel general en el siglo xxı, pero también con el conflicto y el posconflicto, en tanto el cine documental se ha constituido como una herramienta fundamental para la generación y la preservación de la memoria histórica, en la que las comunidades nativas tienen mucho que decir. El asesinato de líderes sociales y campesinos, la falta de un lineamiento claro sobre el reparto efectivo de tierras y las constantes afectaciones del territorio por parte de las industrias extractivas son amenazas que todavía deben afrontar en un contexto en el que el cese del conflicto no ha supuesto el cese de la violencia contra las comunidades. 


\section{DISERTACIONES}

ESTUDIOS

Grupos minoritarios y estigmatizados: diversidad funcional, religiosa, étnica, afectivo-sexual o de identidad de

género en la comunicación

ISSN: $1856-9536$

Doi: https://doi.org/10.12804/revistas.urosario.edu.co/disertaciones/a.11149

Volumen 15, Número 1 / Enero-junio 2022

Versión PDF para imprimir desde

http://revistas.urosario.edu.co/index.php/disertaciones

En este escenario, los procesos de autorrepresentación a través del cine documental en los que las comunidades tienen la iniciativa, trascienden su propia identidad integrando el discurso en la sociedad colombiana, en su relación con el conflicto y en un contexto internacional que ha desarrollado una intensa relación inter-indígena. Pese a que son innegables los logros de la autorrepresentación en la construcción de la imagen de una comunidad, observamos que esta estrategia provoca algunos problemas en cuanto a la efectividad de mensajes generados por colectivos que transmiten los discursos de denuncia mediante narrativas codificadas desde una mirada específicamente indígena. Frente a esta situación, experiencias más ligadas a la correpresentación parecen resultar más efectivas desde el punto de vista de la canalización de mensajes que van más allá de la denuncia y que buscan la sensibilización con aspectos que tienen que ver con la forma de ver el mundo.

\section{Referencias}

1. Barranquero, A., \& González Tanco, E. (2018). Comunicación indígena en América Latina. Anuario electrónico de Estudios en Comunicación Social "Disertaciones", 11(2). https://doi.org/10.12804/revistas.urosario.edu. co/disertaciones/11.2.2018

2. Bengoa, J. (2000). La Emergencia Indígena en América Latina. Fondo de Cultura Económica.

3. Bengoa, J. (2009). ¿Una segunda etapa en la Emergencia Indígena en América Latina? Cuadernos de Antropología Social, 29, 7-22. https://www.redalyc.org/pdf/1809/180913914001.pdf

4. Bermúdez Rothe, B. (1995). Pueblos Indígenas de América Latina y el Caribe: catálogo de cine y vídeo. CLACPI; Biblioteca Nacional de Venezuela.

5. Calvo de Castro, P. (2017). Cine documental en América Latina. Una perspectiva de género. [Tesis doctoral, Universidad de Salamanca]. https://gredos.usal.es/bitstream/handle/10366/137564/DSC_CalvoDeCastroP.pdf?sequence=1\&isAllowed=y

6. Calvo de Castro, P. (2019). Cine documental latinoamericano: conclusiones con base en un estudio trasversal con enfoque contextual y formal de 100 películas documentales. Kepes, 16(20), 126-151. https:// doi.org/10.17151/kepes.2019.16.20.6

7. Calvo de Castro, P. (2021). Cine etnográfico en América Latina. En L. Vilches Marterola (Ed.), Diccionario de Narrativas 2. Narratología, cine, vídeojuegos, medios (pp. 162-181). Penguin Random House.

8. Castells i Talens, A. (2003). Cine indígena y resistencia cultural. Chasqui, Revista Latinoamericana de Comunicación, 84, 50-57. https://doi.org/10.16921/chasqui.v0i84.1505

9. Chaparro Valderrama, H. (2006). Cine colombiano 1915-1933: la historia, el melodrama y su histeria. Revista de Estudios Sociales, 25, 33-37. https://bit.ly/2r4ifeW

10. Díaz Cañadas, G. (2006). El patrimonio fílmico del Chocó. Ministerio de Cultura.

11. Elena, A., \& Mestman, M. (2003). Para un observador lejano: el documental latinoamericano en España. En P.A. Paranaguá (Ed.), Cine documental en América Latina (pp. 79-92). Cátedra.

12. Escárzaga, F. (2004). La emergencia indígena contra el neoliberalismo. Política y Cultura, 22, 101-121. http://www.scielo.org.mx/scielo.php?pid=S0188-77422004000200006\&script=sci_arttext

13. Hernández Delgado, E. (2006). La resistencia civil de los indígenas del Cauca. Papel Político, 11(1), 177220. https://bit.ly/31htFJ5 


\section{DISERTACIONES}

Grupos minoritarios y estigmatizados: diversidad funcional, religiosa, étnica, afectivo-sexual o de identidad de

14. Flores, S. (2013). El Nuevo Cine Latinoamericano y su dimensión continental. Regionalismo e integración cinematográfica. Imago Mundi.

15. Gallois, D., \& Carelli, V. (1992). "Vídeo nas aldeias": a experiência Waiãpi. Cadernos de Campo, 2(2), 25-36. https://doi.org/10.11606/issn.2316-9133.v2i2p25-36

16. Gómez Moreno, P. (2017). Marta Rodríguez, descolonizando la representación documental latinoamericana. Estudios Artísticos, 3(3), 118-135. https://doi.org/10.14483/25009311.12532

17. León Frías, I. (2013). El Nuevo Cine Latinoamericano de los años sesenta: entre el mito y la modernidad fílmica. Fondo Editorial de la Universidad de Lima.

18. Levi-Strauss, C. (2005). Race et Historie. Race et Culture. Editions Odile Jacob.

19. Mateus Mora, A. (2012). Cine y vídeo indígena: del descubrimiento al autodescubrimiento. Cuadernos de cine colombiano, Vol 17A. Cinemateca Distrital.

20. Mora Forero, C., \& Carrillo, A. (2003). Hechos colombianos para ojos y oídos de las Américas. Ministerio de Cultura de Colombia.

21. Nieto Ibáñez, J. (1997). Floro Manco, pionero del cine. Ediciones Uniautónoma.

22. Pizano, D. (2005). Balones que inspiran. Boletín Cultural y Bibliográfico, 42(70), 127-129. http://www.cervantesvirtual.com/obra/balones-que-inspiran-912862/

23. Ramírez, J. (2015). Colombia de Película. Nuestro cine para todos. Ministerio de Cultura de Colombia. https://bit.ly/2Qzki5i

24. Rodríguez, M. (2013). Hacia un cine indígena como metáfora de la memoria de un pueblo y de su resistencia. Revista Chilena de Antropología Visual, (21), 64-79. https://bit.ly/3BbnW97

25. Ruby, J. (2007). Los últimos 20 años de Antropología visual - una revisión crítica. Revista chilena de Antropología Visual, 9, 13-16. http://www.rchav.cl/imagenes9/imprimr/ruby.pdf

26. Ruffinelli, J. (2012). América Latina en 130 documentales. Uqbar Editores.

27. Ruffinelli, J. (2016). Marta Rodríguez: el documental vivo vuelve a vivir. Secuencias, 18, 84-99. https://bit. ly/2rYOEnG

28. Torres San Martín, P. (2015). Cine latinoamericano de mujeres: memoria e identidad. Revista de Estudios de Género, La Ventana, 4, 151-171. https://bit.ly/2KBpGRT 